\title{
Ética, literatura y educación ciudadana para un mundo global
}

\author{
Gustavo Pereira y Helena Modzelewski \\ Universidad de la República (Uruguay)
}

\begin{abstract}
RESUMEN. El concebir al sujeto como un sujeto de reconocimiento recíproco requiere la búsqueda de mecanismos que posibiliten el tránsito del extrañamiento al reconocimiento del otro. Este tránsito se encuentra en el corazón de todo proceso de educación moral y particularmente en el de una educación ciudadana entendida en términos universalistas. Las narraciones literarias propician ese tránsito del extrañamiento al reconocimiento, tanto por la generación de relaciones empáticas tematizadas en la tradición aristotélica, como por los procesos de reflexión crítica que surgen en la estética de Brecht, en la función social de la literatura de Jauss y en la hermenéutica crítica. En virtud de estas razones es por lo que deberían ocupar un rol protagónico en todo proceso de educación ciudadana.
\end{abstract}

Palabras clave: Ética, reconocimiento, literatura, educación
Abstract. The notion of the subject as the product of reciprocal recognition requires mechanisms enabling the movement from the strangeness to the recognition of the other. This movement is the core of every process of moral education, especially the process of educating citizens in universal terms. Literary narrative enables such movement from strangeness to recognition, as much through the generation of Aristotles's empathic relationships, as through the process of critical reflection developed in Brecht's aesthetics, Jauss's social function of literature and critical hermeneutics. In virtue of these reasons, literature should play a central role in every process of educating citizens.

Key words: Ethic, recognition, literature, education

\section{Educación cívica y hermenéutica crítica}

Una larga tradición que comienza con Hegel y que incluye a pensadores provenientes de diferentes áreas del saber tales como Gadamer, Buber, Habermas o Apel en el campo de la filosofía, así como fundadores de la teoría social como G. H. Mead o Durkheim, y figuras como Piaget y Kohlberg en el área de la psicología, coinciden en que el sujeto se constituye en términos de reconocimiento recíproco, es decir, que alguien constituye su identidad solamente en tanto que reconoce a otro, que a su vez lo reconoce. Este reconocimiento recíproco es la clave 
para la construcción de una ética que pueda sentar las bases para una ciudadanía local y global, y que tiene como tarea principal asegurar el reconocimiento de todo ser humano como persona, y por lo tanto como digno de consideración y respeto. Si esto se lograra, estaríamos dando un gran paso para acabar con la discriminación de cualquier tipo, la racial, la de género, la religiosa, y sobre todo una que es poco mencionada en el «nuevo catecismo» de lo éticamente correcto de los organismos internacionales: «la aporafobia, el desprecio al pobre, al débil, al que no tiene qué ofrecer, con qué negociar, qué dar a cambio.»1

En este camino que tiene a la educación ciudadana como objeto, es imprescindible identificar las mejores herramientas que permitan asegurar la transmisión de valores según los cuales todos en tanto que humanos sean igualmente considerados y respetados, de tal modo que al ser cada persona un fin en sí mismo nada justifique su instrumentalización.

Todo proyecto de educación cívica deberá necesariamente recorrer el camino que va del extrañamiento al reconocimiento del otro, y para ello se deberá asumir como característica distintiva de este proceso a la reflexión, concebida como una crítica sobre la tradición y los valores dominantes; si bien esta reflexión no tiene por qué siempre romper con ellos, siempre deberá estar en condiciones de cuestionarlos y de no aceptarlos como un hecho dado. Este proceso asumiría las características de lo que Gadamer entiende por fusión de horizontes, según lo cual la tarea de reflexión crítica, así entendida, implica la comprensión de la tradición abordada desde la situación presente del intérprete que se sitúa en la misma tradición pero en una posición de distanciamiento que permite la introducción de una nueva perspectiva crítica. ${ }^{2}$

A su vez, esta reflexión crítica requiere un parámetro que oriente el progreso interpretativo, puesto que en tanto que todo objeto de interpretación tiene por característica el ser inagotable para el abordaje hermenéutico, se vuelve necesario un criterio que permita discriminar entre las distintas interpretaciones posibles estableciendo cuáles de ellas significan un avance en función de un ideal emancipatorio. ${ }^{3}$ En tal sentido, los presupuestos pragmático-trascendentales del habla postulados por Apel, en tanto que trascendentales y en consecuencia aceptados ya siempre por los hablantes explícita o implícitamente, poseen suficiente fuerza normativa para desempeñar una función crítica. ${ }^{4}$ Esta perspectiva es la que posibilita guiar a ese proceso de reflexión crítica que hemos presentado como lo propio de la educación ciudadana.

Por otra parte, esta educación cívica en clave de hermenéutica crítica introduce el reconocimiento recíproco como el supuesto más importante de su operativa,

\footnotetext{
${ }^{1}$ Cortina A., Hasta un pueblo de demonios, Taurus, Madrid, 1998, p. 53.

2 Cf. Gadamer H. G., Verdad y método, vol. 1 Sígueme, Salamanca, 1997, p. 377.

3 Cf. Papel K. O., La transformación de la filosofía, vol. 1, Taurus, Madrid, 1985, pp. 40-48. Desarrollo esta discusión con mayor detalle en Pereira G., «Interpretación constructiva y realismo», Areté, XV, 2, 2003, pp. 243-265.

4 Cf. Cortina A., Razón comunicativa y responsabilidad solidaria. Ética y política en K. O. Apel, Sígueme, Salamanca, 1995, p. 118.
} 
ya que para toda interpretación es necesario contar con dos seres dotados de competencia comunicativa que se reconocen mutuamente en su capacidad para argumentar. A su vez, en función de las condiciones de simetría que el reconocimiento recíproco requiere, se impone como rasgo distintivo una radical apertura a la alteridad que introduce toda la particularidad y diferencia que afecta a cada posible involucrado. En consecuencia, una educación cívica bajo estas coordenadas implica que temas tales como la homosexualidad, las diferencias de género, las particularidades de los discapacitados, el sufrimiento del pobre entre otros, deben ser fuertemente tematizados como forma de asegurar lo más básico para una reflexión ciudadana: la inclusión del otro. Finalmente, esta perspectiva debe ser entendida en sus términos radicales, por lo que debe exceder a la localidad para asentarse en lo global; las crecientes posibilidades de interconexión de nuestro mundo demandan cada vez más de esta radical inclusión de la alteridad como clave para el enriquecimiento humano y como base para el entendimiento. Una ciudadanía intercultural, en otras palabras, se hace imprescindible.

En consonancia con esta perspectiva, el objetivo de la educación cívica deberá ser educar la mirada de los ciudadanos para poder reconocer la humanidad en aquellas dimensiones en que suele ser negada. Es un proceso que apunta a acostumbrar al ciudadano a reconocer al otro que ha sido tradicionalmente negado, y en consecuencia pretende reeducarlo en una nueva ciudadanía. De esta forma, a partir de esta nueva mirada inclusiva tanto de la marginación económica encarnada en la pobreza como de minorías étnicas, sexuales y religiosas, se asegurará el reconocimiento del otro y su igual dignidad.

\section{La literatura y el reconocimiento del otro}

El proceso de extrañamiento-reconocimiento a recorrer en todo proyecto de educación ciudadana debe asegurar la identificación con aquel que es extraño, ajeno y que por lo tanto podría llegar a ser objeto de un tratamiento no igualitario. La clave para asegurar este tránsito es encontrar herramientas que propicien una relación empática con el extraño de tal manera de poder sentir su sufrimiento, su marginación o su infelicidad como la propia, como algo que podríamos vivir, como una posibilidad real dentro del campo de posibilidades que afectan a quienes efectivamente reconocemos y que por ello consideramos dignos de un tratamiento igualitario.

Las narraciones en general y la literatura en particular son una de esas herramientas que permiten recorrer el proceso de extrañamiento al reconocimiento del otro, y en este rasgo distintivo reside su utilidad para cualquier proyecto de educación ciudadana. Carlos García Gual5 ilustra claramente cómo la literatura en el

5 Cf. García Gual C., «Teatro trágico y educación democrática en Atenas», en Conill J. y Crocker D. (editores), Republicanismo y educación cívica. ¿Más allá del liberalismo?, Comares, Granada, 2003, pp. 3-19. 
caso especial del teatro puede tener un rol formativo de ciudadanos, a través del ejemplo de la tragedia griega en la sociedad ateniense de la época clásica. Allí el arte escénico tuvo una función espiritual y cívica que se manifestaba en las fiestas de Dioniso.

Esas obras eran dirigidas, representadas y juzgadas por representantes calificados de las diversas tribus que conformaban la ciudad, por lo cual puede decirse que la ciudad se representaba a sí misma ante el público. Lo que hacía la tragedia era provocar en los espectadores (los ciudadanos) una reflexión profunda sobre los valores de la vida en común, valores que se veían cuestionados en la escena a través de los conflictos que se les presentan a los héroes míticos. Al tener que optar el protagonista entre dos principios esenciales y sin embargo antagónicos en la situación de la tragedia, el público reflexionaba acerca de la importancia de cada principio y su jerarquización en su escala de valores.

Si bien es cierto que los espectadores no podían identificarse con los protagonistas en sus roles pues eran reyes y reinas de otras épocas, de cualquier manera, siguiéndolos en el desarrollo de sus destinos, contemplando sus pasiones y en el trasfondo la actuación de los dioses, el público ateniense reflexionaba sobre la condición humana, la libertad y la vida, y experimentaba emociones acompañando a los héroes en su dolor. De esta forma, sirviéndose de los mitos tradicionales retomados, en las tragedias se tematizaba la convivencia política, la justicia, la hospitalidad, las venganzas e intrigas familiares, las relación con los dioses, la relación de los sexos, los desastres de la guerra, la imagen del otro, siendo éstos sólo algunos ejemplos. Ante los problemas planteados los espectadores seguían en su resolución a los protagonistas y los resolvían mentalmente junto con ellos, consistiendo justamente en eso la enseñanza.

Esto de la educación por medio del arte no era algo nuevo. Desde la época homérica los poetas habían sido los verdaderos educadores del pueblo griego. «Mucho más que los sacerdotes, ocupados en sus ritos y ceremonias; a la par de los legisladores, mucho más locales; y antes que los filósofos, que nunca tuvieron su arraigo popular.» 6 En la época de mayor esplendor democrático el teatro fue el espectáculo cultural más importante. Allí se expresaba una visión del mundo, que se presentaba al público para reflexionar, y los dramaturgos atenienses trascendieron la condición de poetas para convertirse en pensadores al exponer en sus obras su propia visión del mundo haciendo uso de la materia mítica y recreándola. Allí se expresan los conflictos más hondos de la vida humana, de la ética y la política, con el pretexto de mostrar relatos míticos. Incluso Aristóteles, que escribió cuando la tragedia ya había desaparecido como factor educativo en la polis, remitía especialmente a las tragedias euripideas para ilustrar puntos éticos en su Ética Nicomáquea, admitiendo de esta manera el carácter reflexivo que tenían las tragedias en la vida cívica ateniense. Pero en particular su posición sobre la función

\footnotetext{
6 Ibid., p. 8 .
} 
social del arte trágico se pone de manifiesto cuando presenta su teoría sobre la catarsis. En sus escritos de historia natural, Aristóteles usó mucho el término en su significado médico de purificación y purga, pero en el caso de la tragedia lo amplió por primera vez y lo aplicó a un fenómeno estético, especificándolo como una especie de liberación o sosiego que el hombre siente a través del arte. «Es, así, la tragedia imitación de una acción elevada y perfecta, de una determinada extensión, con un lenguaje diversamente ornado en cada parte, por medio de la acción y no de la narración, que conduce, a través de la compasión y del temor, a la purificación de estas pasiones.»7

Como Aristóteles no da una definición más detallada de la catarsis en la tragedia, ha de entenderse que adopta aquí la palabra en el sentido general corriente de «depuración, limpieza, purificación», y también «aclaración» (en el sentido de remoción de impurezas). De esta manera, al decir que éste era el efecto de la tragedia en los espectadores, si bien se refería a sus emociones, estaba soslayadamente indicando su carácter didáctico, ya que a través del drama se «aclara» el entendimiento. ${ }^{8}$

El Estado ateniense cuidaba celosamente los detalles de organización de estas fiestas dionisíacas, que el Estado mismo costeaba debido a que consideraba a las representaciones teatrales como una instancia educativa cívica superior a la de la enseñanza de la lectura y escritura, que sí eran dejadas en manos de particulares a los que se debía pagar. Este hecho histórico nos remite a una potencial obligación que deberían asumir los Estados contemporáneos para la educación de sus ciudadanos, utilizando la literatura y el drama como medios por excelencia Tal deber puede fundamentarse en que ninguna sociedad democrática puede prescindir de ciudadanos reflexivos para sus condiciones mínimas de operatividad, y las narraciones, en virtud de un conjunto de características internas se califican como instrumento privilegiado para la educación cívica.

En este momento se vuelve necesario ahondar en esa peculiaridad que nos permite postular a las narraciones como herramienta educativa ciudadana, y en tal sentido debe decirse que lo distintivo de las obras literarias reside en que invitan al lector a colocarse en la posición del otro y a adquirir sus experiencias; su interpelación del lector les posibilita ser eslabones entre éste y los personajes, activando las emociones y la imaginación, que conducen a ver de cerca muchas cosas que fuera de este espacio nos son ajenas. A través de la literatura se accede al más básico punto en común de todos los seres humanos: nuestra condición de seres libres e iguales. Obviando el color de la piel, la religión, la posición socio-económica, la literatura llega a conmover por medio de la manifestación de lo que compartimos como humanidad: los sentimientos, la conciencia, la razón. Por lo tanto, la literatura tiene como característica relevante para una ética global de

7 Aristóteles, Poética, Monte Ávila, Caracas, Traducción y notas Ángel J. Cappelletti, 1449 b 24-29.

${ }^{8}$ García Gual, op. cit., p. 17. 
reconocimiento recíproco el ser capaz de posibilitar el tránsito del extrañamiento al reconocimiento, al permitir acceder a través de la imaginación a la vida de otras personas que podrían haber sido nosotros mismos.

Pero no todos los caminos del pensamiento contemporáneo conducen al reconocimiento, y en esto se debe ser muy enfático, ya que a la vía que nos conduce a la literatura como medio óptimo para la generación de estas relaciones empáticas se llega después de excluir como posible alternativa a cualquier tipo de aproximación racional entendida en términos de ajuste de medios a fines. Este tipo de enfoques reducen la racionalidad a racionalidad estratégica, dejando los fines a la discreción individual y, en consecuencia, bien pueden llegar a justificar la cosificación e instrumentalización del otro en tanto eso habilite a una optimización de los fines elegidos.

El poder empático que oficia de mediador en el tránsito del extrañamiento al reconocimiento requiere de la introducción de la imaginación, que es la que posibilita al sujeto colocarse en el lugar del otro e incorporar su situación como propia. Por lo tanto, este movimiento que va del extrañamiento al reconocimiento debe superar nuestras propias actitudes objetivantes que tienden a cosificar al otro y que incluso pueden ser alimentadas por cierto tipo de acercamientos que lo reducen a un objeto. Por ejemplo, nuestra subjetividad se enfrenta con serios obstáculos para el reconocimiento en el tratamiento tradicional que hace la economía utilitarista de las personas, o en el distanciamiento propio de las obras de ciencias sociales. Una aproximación histórica o sociológica a una situación de marginación o discriminación tiende a presentar las situaciones en términos descriptivos y eso, en tanto que deja las emociones al margen, genera un distanciamiento que opera como un obstáculo para el reconocimiento. Sin embargo, la literatura, al promover la identificación del lector con los personajes a través de las reacciones emocionales, tiende a derribar estos obstáculos generando un fuerte proceso de identificación y reconocimiento del otro.

En este momento, y dado el peso que tienen las emociones en este enfoque, es necesario evaluar si la contradicción emociones-racionalidad es sustentable una vez que abandonamos el terreno de la reducción de la racionalidad a la racionalidad estratégica que tiene a la matematización del mundo como paradigma de su tendencia reductiva.

\section{Emociones y narración}

La literatura y su poder empático se encuentra intrínsecamente ligada a las emociones, tanto desde la perspectiva del lector en el que se genera una respuesta a ellas, como en la motivación que lleva al autor a concebirlas, y es a través de esta constitución emocional que las obras literarias pueden formar vínculos de compasión e identificación, induciendo al lector o al espectador a experimentar piedad y 
temor por los personajes, y también temor por sí mismos, al ver al héroe vulnerable en la misma medida en que ellos mismos, lectores, lo son. 9

Pero a pesar de este poder empático que provoca el tránsito del extrañamiento al reconocimiento, las emociones han sido consideradas como no deseables para la vida pública, debiendo ser confinadas a la vida privada. Esto cuenta con antecedentes tan significativos como el propio Platón, y en nuestros días se manifiesta en la racionalidad reductiva propia de la racionalidad estratégica que, teniendo al fisicalismo y la matematización como modelo, margina y excluye como carente de sentido a todo aquello que no pueda ser explicado con estos cánones. El caso del utilitarismo, y en particular el de la teoría de la elección racional en su influencia más allá de la economía, se manifiesta en posiciones como la de Richard Posner, quien sostiene que solamente pueden respetarse las elecciones de la personas como racionales si podemos demostrar que se adecuan al concepto utilitarista de maximización racional, es decir, que las personas son maximizadoras racionales de la satisfacción y no reflejan la influencia de los factores emocionales. ${ }^{10}$

Pero saliendo de la esfera de la racionalidad instrumental que pauta los ejemplos más recientes, es posible referir a las más antiguas críticas a las emociones formuladas por Platón, quien al igual que los estoicos asociaba las emociones a la falta de estabilidad. Estos filósofos sostenían como ideal de ciudadano a alguien estable e inmutable ante los cambios de la fortuna, ya que en tanto que lo único verdaderamente importante es la virtud intrínseca a la persona, la fortuna, los eventos que suceden externamente a ella no deben ser considerados importantes, porque nada puede vulnerar el interior de una persona sabia. En la medida en que éste era el modelo de ciudadano, Platón afirmaba que la mayor parte de la literatura existente se debía desterrar de la ciudad ideal. La razón para ello es que la literatura tiende a encarar los acontecimientos que afectan a personas vulnerables como profundamente significativos, haciendo además participar al público de su fortuna, y en definitiva proporcionando un mal ejemplo a imitar en la vida, es decir, conduciendo la educación cívica por el camino incorrecto: el que propicia las emociones. ${ }^{11}$

Por lo tanto, si se toma tanto la perspectiva de la teoría de la elección racional como la platónica o estoica, la literatura no debería ser una disciplina a desarrollar institucionalmente en un Estado. Fomentar el desarrollo de las emociones a través de la literatura no es algo a lo que deba apuntarse desde las instituciones públicas; la literatura debería quedar reducida a la esfera de la vida privada donde asumiría el rol placentero de un pasatiempo, pero nada más.

\footnotetext{
${ }^{9}$ Cf. Nussbaum M., Justicia Poética, Andrés Bello, Barcelona, 1997, pp. 85-86.

${ }^{10}$ Cf. Richard Posner, The Economics of Justice, Harvard University Press, Cambridge, Mass., 1981, p. 1-2. También Nussbaum refiere la instrucción que se le da a un jurado en el estado de California en la década de los 80. En la fase penal se le advierte al jurado que «no se debe guiar por el mero sentimiento, la conjetura, la compasión, la pasión, el prejuicio, la opinión pública ni el sentimiento público»(op. cit., p. 87).

11 Cf. Nussbaum, op. cit., p. 91.
} 
Estas posiciones son rechazadas por Nussbaum, quien en primer lugar sostiene que las emociones no están divorciadas del juicio puesto que están provocadas por creencias. Sostiene que las emociones contienen una dirección hacia un objeto que a su vez es presentado a través de una descripción intencional; por ejemplo, «mi cólera no es un mero impulso, un hervor de la sangre: está dirigida contra alguien, a saber, una persona que en mi percepción me ha agraviado. El modo en que veo a esta persona es inherente a la naturaleza de mi emoción.»12 Por lo tanto, las emociones pueden ser explicadas como modos de percibir que se encuentran íntimamente relacionados con un conjunto de creencias acerca de su objeto. Parece prácticamente imposible el intentar discriminar entre distintas emociones sin apelar a un conjunto de creencias que se vinculan con la experiencia y que determinan si, por ejemplo, el sentimiento de felicidad que se siente debe llamarse amor o gratitud. Consecuentemente, esto habilita a la introducción de la dimensión cognitiva de las emociones, donde las emociones, para ser evaluadas, requieren que se inspeccione las creencias o juicios relevantes, cancelando la posibilidad de que sean consideradas irracionales en el sentido de divorciadas de la cognición y el juicio. ${ }^{13}$

Por su parte, la objeción estoica que señalamos más arriba refiere al énfasis que realiza la literatura en las circunstancias externas que afectan a las personas, siendo bajo esa perspectiva una influencia perniciosa, ya que lo único necesario para una vida virtuosa y para una ciudadanía ejemplar se encuentra en nuestro propio interior. Es más, estas creencias sobre el peso de las circunstancias externas son consideradas falsas y teniendo el terrible efecto de quitarle confianza y estabilidad a la acción del ciudadano. Pero una perspectiva como ésta fracasa rotundamente a la hora de ofrecer buenas razones para participar en la vida ciudadana, para buscar la justicia social o perseguir el bien común, ya que la única forma de desechar el peso de las circunstancias externas es eliminando el reconocimiento de la propia vulnerabilidad, y si esto sucede y se constituye un sujeto virtuoso que prescinda de los avatares de la fortuna, poco importa si vive en democracia o en dictadura, si la pobreza es un flagelo para su sociedad o si la corrupción destruye todas las bases de una posible idea de bien común. Por lo tanto, si estas consecuencias son rechazables porque no nos es indiferente ni la pobreza, ni la vitalidad de la democracia, ni la corrupción, entonces debemos reconocernos como sujetos vulnerables a las circunstancias que necesitan bienes externos además de bienes internos y que en función del reconocimiento de nuestra fragilidad incorporamos la posibilidad de sentir por los otros compasión, gratitud o piedad, ya que podemos ser afectados de igual forma que ellos por las circunstancias. El reconocimiento de que uno podría sufrir lo que otro rompe con las bases del egoísmo y propicia el desarrollo de la piedad o compasión en los individuos necesario para una plena racionalidad social.

12 Ibid., p. 94.

13 Cf. Ibid. , p. 95. 
Por último, las emociones tienen la deseable consecuencia de influir en la actuación de mejores gobernantes al romper con el paradigma dominante de la elección racional e introducir un fuerte peso de la compasión. Para alguien puramente racional, es decir, sin emociones, podría llegar a considerarse todo un éxito que en una población de un millón de habitantes murieran de hambre sólo veinticinco personas. Sin embargo, un sujeto que pusiera en su razonamiento la compasión pensaría que para los veinticinco que mueren de hambre no es relevante lo que le sucede a la mayoría y, aun más importante, que éstos tienen un valor intrínseco que vuelve imperativo asegurar su subsistencia. En el primer caso, el gobernante subsidiario de la teoría de la elección racional no propiciaría ningún cambio al estar satisfecho con el resultado, mientras que en el segundo caso se introduciría una percepción diferente del problema puesto que a través de la compasión las personas no serían simplemente números, no habría una reducción matemática, sino que éstas tendrían valor en sí, y en función de ello el gobernante intentaría llegar al cero número de personas padecientes. ${ }^{14}$

Por todas esas razones puede decirse que el estudio de la literatura, y a través de ella el desarrollo de las emociones en los ciudadanos, contribuiría a una mejor sociedad. Volviendo a lo que decíamos más arriba, la literatura utiliza a las reacciones emocionales como medio que permite asegurar la identificación del lector con los personajes, y este hecho tiende a derribar los obstáculos generados por los procesos de cosificación del otro propios de algunos abordajes de ciertas disciplinas o de algunas convicciones dominantes, generando en tal proceso una fuerte identificación y reconocimiento del otro.

Las narraciones logran esto a través la apelación a un lector implícito que comparte con los personajes un trasfondo de expectativas que les posibilita generar fuertes lazos de identificación y empatía con ellos, que a la vez producen un fuerte proceso de integración. ${ }^{15}$ Estas narraciones introducen al lector en el mundo cotidiano de los personajes, que se constituyen en su objeto de interés y de profunda comprensión, y acercan al lector a lo que es común y próximo y que debido a la extrañeza de ese universo suele ser ignorado y rechazado. A través de estos relatos somos testigos cercanos de lo que afecta a estos personajes que presentan una vida compleja llena de obstáculos y oportunidades, inmersa en un mundo cualitativamente rico e irreductible en su diversidad. El movimiento del extrañamiento al reconocimiento que las narraciones propician se encuentra determinado tanto por el acceso al universo narrativo a través de la riqueza de la individualidad de sus personajes y su vida cotidiana, como por «su empeño por no describir los hechos de la vida desde una perspectiva externa de distanciamiento -como si fueran los actos y movimientos de piezas mecánicas- sino desde dentro, como investidos de la compleja significación que los seres humanos atribuyen a sus propias vidas.»16 Este proceso nos conduce

\footnotetext{
14 Cf. Ibid., p. 102

15 Cf. Ibid., p. 32.

16 Ibid., p. 60.
} 
a reconocer la igual humanidad y la igual dignidad de hombres y mujeres de otras partes del mundo, de clases sociales diferentes, que han realizado opciones sexuales diferentes a las nuestras o que tienen creencias religiosas distintas.

Pero para afirmar una idea ya presentada, es preciso decir que además de las características intrínsecas de las narraciones que posibilitan el pasaje del extrañamiento al reconocimiento, es necesaria una condición inherente al propio sujeto que experimenta este proceso, y es la asunción de la propia insuficiencia, de la propia posibilidad de ser afectado como el otro. Es este hecho el que posibilita el ingreso de emociones que propician el surgimiento de sentimientos empáticos, y de ahí el reconocimiento. El supuesto de la vulnerabilidad de la vida humana y de la necesidad de bienes externos para tener una buena vida es lo que habilita al surgimiento de la identificación con la desgracia ajena en tanto que es una posibilidad para el propio afectado. Una de las más iluminadoras reflexiones de Rousseau sobre este punto se encuentra en su observación de que el no creer o sentir nuestra propia vulnerabilidad es lo que lleva a la indiferencia social: «¿Por qué los reyes no sienten piedad por sus súbditos? Porque cuentan con no ser nunca humanos. ¿Por qué los ricos son tan despiadados con los pobres? Porque no temen empobrecerse. ¿Por qué un noble siente tanto desprecio por un campesino? Porque él nunca será campesino. [...] La piedad del ser humano lo vuelve sociable [...]»17

Esta vulnerabilidad es lo que genera un fuerte sentimiento de empatía con los diferentes personajes de una novela y lo que propicia el reconocimiento.

\section{La empatía según Brecht}

En este punto del desarrollo y dado que la empatía aparece como el concepto central que propicia el tránsito del extrañamiento al reconocimiento necesario para una educación cívica, puede ser de utilidad referirse a las críticas de Brecht a este fenómeno que el teatro dramático propiciaba en la antigüedad. Brecht contrasta dos tipos de teatro: el teorizado en la tradición que Aristóteles inicia, y el modelo que él presenta y utiliza en su propio teatro y sus escritos sobre teatro. En tal sentido sostiene que las prácticas dramáticas aristotélicas llevan al espectador a concluir que el sufrimiento humano es inevitable, mientras que en su propuesta el sufrimiento se presenta como algo que puede cambiarse a través de la transformación social de las instituciones políticas. ${ }^{18}$

Esta diferencia sustancial de enfoques se manifiesta más claramente si nos centramos en la idea de empatía que en Aristóteles se ve expresada cuando se siente temor por una persona que la audiencia cree que es «como ellos mismos»19,

17 Ibid., p. 100, de Rousseau, Emilio, libro 4.

18 Cf., Brecht B., Brecht on Theatre. The Development of an Aesthetic, Hill and Wang, New York, 1992, Edición y traducción de John Willett, p. 71.

19 Aristóteles, Poética, 1453a 5. 
o cuando la gente «siente piedad por aquellos como ellos mismos en edad, carácter, hábitos, rango, nacimiento; porque en todos estos casos algo parece aplicarse a sí mismos [...] la gente siente piedad de la cosas que le ocurren a otros siempre y cuando temen por sí mismos» ${ }^{20}$. Como hemos visto, aquí se encuentra la base de sustentación para el argumento de Nussbaum que hemos presentado, puesto que al sentir piedad y temor por el protagonista, el espectador toma al personaje como modelo para sus propias posibilidades en la vida.

En franca contraposición, el teatro de Brecht apunta a evitar lo que él llama «empatía» (Einfuhlung) porque cree que ese modo de respuesta es una barrera a la reflexión crítica de la dimensión social de la tragedia, porque el espectador ve la acción de la obra desde el punto de vista del protagonista, y así pierde una perspectiva más amplia. Si bien la posición de Brecht varió a lo largo de su carrera, permaneció constante el argumento de que la empatía con los personajes en el teatro lleva a un confinamiento emocional antes que a una apertura a la reflexión crítica. El espectador queda atrapado en la perspectiva del personaje con la empatía, y esto no le permite la libertad de consideración de todos los elementos para entender la situación del personaje.

Básicamente, las objeciones de Brecht hacia la empatía en Aristóteles son del siguiente orden: a) para facilitar una perspectiva crítica sobre las relaciones sociales representadas en el teatro, éste debería ir más allá de revelar los pensamientos y sentimientos del protagonista para considerar una red social más amplia en la cual el protagonista opera, b) las prácticas estéticas aristotélicas no permiten al espectador moverse de la perspectiva individual a la social, c) por lo tanto, el teatro aristotélico utiliza una empatía que no permite a la audiencia involucrarse en la reflexión sobre las relaciones sociales representadas en la obra.

En su teatro épico Brecht lleva adelante el propósito de forzar al espectador a tomar una decisión ante los diferentes estados de cosas que observa en la obra, por lo que el objeto de la representación es facilitar la formación de una opinión a través de esa hipotética toma de decisión. ${ }^{21}$ Consecuentemente, el pensamiento activo e independiente del espectador en relación a los personajes y eventos era una finalidad esencial en las obras de Brecht.

A partir de esta posición, las críticas de Brecht a la empatía utilizada por Aristóteles nos hacen considerar si el uso de la empatía con los personajes puede ser un modo efectivo de alentar la reflexión sobre las causas sociales de la desgracia humana. Los propios trabajos de Brecht muestran que involucrarse con los personajes puede ser útil para reflexionar sobre las causas sociales del sufrimiento. Sin embargo, tiende a sostener que la literatura que vaya a ser utilizada para este propósito necesita ser suplementada con otros mecanismos que permitan que, además de provocar la empatía, el espectador o lector considere las acciones y pensamientos del personaje como parte de un más amplio contexto social. En este

20 Aristóteles, Retórica, Madrid, Gredos, 1990, Traducción y notas Q. Racionero, 1386a 13.

21 Cf. Brecht, op. cit., p. 128. 
punto creemos que no existe una distancia conceptual real entre Aristóteles y Brecht en lo que hace a la empatía, ya que en el caso de Aristóteles la empatía prescinde de este contexto social del que habla Brecht debido a las características de la polis; estamos hablando de una sociedad fuertemente integrada de tal forma que puede darse sentado ese contexto social. Sin embargo, en nuestra contemporaneidad, el incremento de complejidad de las sociedades modernas obliga a una referencia explícita al contexto social, que es la exigencia que impone Brecht. Por lo tanto, si el concepto de empatía en Aristóteles es sometido a un proceso interpretativo que propicie una fusión de horizontes, seguramente tendríamos un concepto cercano a la reflexión de Brecht con la introducción de ese contexto complejo que a partir de la modernidad no puede darse por sentado. De ahí que bien podríamos conectar el concepto de empatía con el de reflexión crítica en Brecht, que nos conducirá directamente a la tesis VII de Jauss sobre la función social de la literatura. Pero antes de ingresar en este último momento del desarrollo conceptual, detengámonos en un ejemplo que nos permitirá ver cómo opera esta empatía que a través de la reflexión crítica provoca el reconocimiento.

\section{La indigencia en Auster}

Como forma de ilustrar el hecho de que la propia vulnerabilidad es lo que genera un fuerte sentimiento de empatía con los diferentes personajes de una novela y a su vez lo que propicia el reconocimiento, presentaremos un ejemplo a partir de la compasión que produce la indigencia.

Paul Auster en El Palacio de la Luna y en El país de las últimas cosas nos acerca a la indigencia que encontramos a diario en nuestras ciudades, y que en virtud del acostumbramiento que produce el contacto casi permanente con esa realidad, suele propiciar cierta insensibilidad. Las ciudades de América Latina, cada vez más golpeadas por la desigualdad, son en aumento habitadas por seres que mendigan en las esquinas, revuelven la basura y se acurrucan en portales para pasar la noche. Ya nadie se acerca a ellos, ya ni siquiera se los mira con fastidio o pena, como podía ocurrir en el pasado. Forman parte de nuestro paisaje citadino y justamente el proceso de integrarlos al entorno como un objeto más es lo que nos vuelve insensibles, indiferentes ante lo que esta gente puede llegar a sentir respecto al estilo de vida que llevan. Se llega a creer que viven de esa manera por elección, o al menos que están tan acostumbrados a ello que ya no les molesta. Esta actitud impasible lleva a su consecuencia más peligrosa, el conservadurismo, la justificación del estado de cosas a través de algo así como una necesidad natural, en definitiva a la cancelación de toda posibilidad de cambiar estas situaciones.

Pero veamos cómo ilumina Auster esta realidad. Su personaje en El Palacio de la Luna, Marco Fogg, se deja caer en la indigencia por la desidia que lo domina una vez que su único familiar, el tío que le servía de referente, fallece. Si bien no es muy clara la causa por la cual un joven universitario se niega a salir a buscar 
una manera de ganarse la vida, y eso hace un poco más difícil la empatía total con el personaje, al focalizarnos en los eventos que van marcando su caída el lector llega a comprender varias instancias que da por sentado en la vida real.

El alimentarse de los residuos es uno de los incidentes más atroces que las grandes ciudades han incorporado con insensibilidad. Auster nos recuerda que el vagabundo que lo hace es un ser humano que al igual que el lector siente asco y vergüenza al comer de la basura, y en virtud de ello reproduce en el lector tales sentimientos.

«Tardé un tiempo en adaptarme, pero una vez que acepté la idea de llevarme a la boca algo que ya había tocado la boca de otro, encontré un sinfín de comida a mí alrededor. [...] Para combatir mis remilgos empecé a ponerles nombres graciosos a los cubos de basura. Les llamaba restaurantes cilíndricos, cenas de la suerte, paquetes de asistencia municipal, cualquier cosa que me evitara decir lo que realmente eran.» 22

La humanidad vuelve a situarse en el vagabundo de la novela, que pasa de ser Marco Fogg a cualquier vagabundo que se nos cruza en la calle. Una vergüenza subrepticia se apodera del lector, y lo lleva a comprender que la condición de vagabundo no significa la aceptación de ese estilo de vida como algo normal, y sobre todo que es un estado de cosas que si pudiera cambiar lo haría.

Pero esta vergüenza que siente el protagonista se extiende a otro aspecto sumamente significativo de la indigencia y que es el del propio aseo. «Una mañana en que la lluvia lo había empapado, Marco decidió entrar a la sala de lectura de la biblioteca pública confiando en que el calor que hacía allí dentro contribuyera a secarle la ropa. Esto ocurrió tal como él lo había esperado, aunque con una consecuencia desagradable que no había previsto: la ropa comenzó a oler, con ese olor característico de los vagabundos.

Era como si todos los pliegues y arrugas de las prendas hubiesen decidido de repente contarle sus secretos al mundo. Esto no me había sucedido nunca antes y me horrorizó descubrir que un olor tan nocivo pudiera venir de mi persona. [...] Seguí hojeando las páginas de la Encyclopaedia Britannica, con la esperanza de que nadie lo notara, pero estos ruegos no fueron escuchados. Un anciano sentado frente a mí alzó la cabeza de su periódico y comenzó a olfatear el aire, luego me miró, con cara de asco. Por un momento estuve tentado de levantarme de un salto y reprenderle por su grosería, pero comprendí que me faltaba la energía necesaria. Antes de darle la oportunidad de decir nada, me puse en pie y me fui».23

El lector, puesto junto con el narrador en el lugar de la persona que hiede, comprende con compasión y, lo que es más, empatía que el mal olor de un vagabundo no es una ofensa hacia los demás miembros de la sociedad por parte del indigente, sino que es experimentado como una vergüenza de la que es difícil

22 Auster P., El Palacio de la Luna, Anagrama, Barcelona, 1996, p. 71.

23 Ibid., p. 78-79. 
librarse si no se tiene un hogar decoroso donde quitarse la ropa, darse una ducha, vestirse con ropa limpia, lavar la que estaba sucia, esperar a que esté seca. Pensándolo así, una misión tan sencilla como mantenerse higienizado es bastante compleja si no se tiene un techo estable ni dinero para comprar más mudas de ropa. La posible acusación de desidia desaparece de la mente del lector al comprender la dificultad de realizar hechos cotidianos tan simples si se carece de posesiones que tantas veces se dan por sentadas. Estas posesiones de hecho no vienen con el individuo, sino que requieren dinero $y$, en consecuencia, una cierta adaptación al sistema social en el que se vive, adaptación de la que algunos individuos bien pueden carecer.

En El país de las últimas cosas también se tematizan aspectos de la vida de personas viviendo bajo la línea de pobreza, pero a diferencia de El Palacio de la Luna no nos encontramos ante una novela realista, y ésta tal vez sea su diferencia más significativa. Mientras que El Palacio de la Luna está ambientada en un New York contemporáneo y fácilmente rastreable a través de los lugares mencionados, El país de las últimas cosas retrata una ciudad en los confines del mundo, atemporal, aislada del resto de las naciones, que no tiene nombre ni ubicación en el mapa, a donde raramente llegan visitantes y de la cual nadie puede escapar. El lector encuentra dificultosa la identificación con esta realidad, ya que es muy poco probable que alguien se encuentre en una situación de ese tipo.

Sin embargo, el personaje se nos hace más cercano que Marco Fogg, ya que mientras Marco caía en la indigencia por una especie de desidia que el lector promedio calificaría de perezosa e inaceptable, Anna, quien escribe la larga carta en la que consiste el relato, es una joven completamente normal de una sociedad occidental opulenta, con las características e inquietudes que cualquier joven real de esa edad seguramente tiene. Esta mayor cercanía de Anna es lo que vuelve más violenta la situación de marginación que ella debe padecer en el país sin nombre, y junto con ella somos capaces de vivir con sorpresa y repulsión el proceso descendente ante el cual nada puede hacer. A través de los ojos de Anna, el lector comprende la importancia de ciertos detalles de la vida de una persona que se dedica a la recolección de basura, a los que con seguridad antes jamás habría prestado atención y que por su propia cuenta nunca habría comprendido si no fuese guiado por la mano del novelista. Pormenores como el siguiente:

«El instrumento preferido para transportar la basura es el carro de supermercado, similar a aquellos que tenemos allí, en casa. [...] Un vehículo más grande resultaría demasiado pesado para transportar cuando se llenara y uno más pequeño requeriría demasiados viajes al depósito. [...] Como consecuencia, estos carros tienen una gran demanda y el primer objetivo de un recogedor de basura es conseguir uno. [...] incluso si logras conseguir el carro, debes procurar mantenerlo en buen estado, las calles estropean muchísimo el equipo y hay que tener especial cuidado con las ruedas». ${ }^{24}$

\footnotetext{
${ }^{24}$ Auster P., El país de las últimas cosas, Anagrama, Barcelona, 1994, p. 44-45.
} 
Un nuevo mundo se abre ante los ojos del lector. Un mundo que, si bien desagradable e improbable por lo general para quien tiene acceso al libro donde estos hechos se relatan, al estar contados por alguien que podría compartir el mismo universo de posibilidades que el lector es que provocan la compasión, se siente como si la carta de Anna fuera escrita para él mismo. A partir de ese momento, el proceso iniciado es prácticamente irreversible: difícilmente podrá el lector sensible mirar a una persona sumida en la pobreza juntando basura en algún precario vehículo rodado, sin recordar a Anna y pensar en la dificultad que conseguir o construir aquel carro debe de haber implicado, sin pensar que la vida de ese mísero individuo depende de ese vehículo y en la tragedia que significaría algo tan básico como perder una rueda.

\section{Función social del arte, ficción y mundo de la vida}

En este punto realizaremos el ajuste teórico final en un intento por brindar una explicación acabada de por qué es que la literatura tiene este potencial de generación de reconocimiento. Como lo anunciamos más arriba, cerraremos el concepto de función social de la literatura a través de la introducción de la tesis VII de Jauss, que complementa la reflexión de Brecht y coincide con nuestra posición metodológica básica de hermenéutica crítica. En tal tesis Jauss sostiene que:

«La tarea de la historia de la literatura solamente concluye cuando la producción literaria no es presentada sólo sincrónica y diacrónicamente en la sucesión de sus sistemas, sino considerada también como historia especial incluso en la relación que le es propia respecto a la historia general. [...] La función social de la literatura se hace manifiesta en su genuina posibilidad allí donde la experiencia literaria del lector entra en el horizonte de expectativas de la práctica de su vida, preforma su comprensión del mundo y repercute de ese modo en sus formas de comportamiento social». ${ }^{25}$

En esta tesis radica lo distintivo de la función social de la literatura. Para presentarla con mayor detalle, Jauss sostiene que la relación funcional entre la literatura y la sociedad es tradicionalmente presentada por la sociología literaria de una manera limitada, reduciendo la literatura a una función mimética de la realidad, siendo por lo tanto el paradigma el «realismo» del siglo XIX. Pero la interpretación de la literatura como mimesis deja escapar su función de creación social $^{26}$, al marginar la pregunta acerca de cómo la literatura contribuye a moldear la imagen de la sociedad que está en su origen.

Jauss piensa que su concepto de horizonte de expectativa es la respuesta a la búsqueda de ese vínculo. En este concepto se incorpora la noción de experiencia

25 Jauss H. R., «La historia de la literatura como provocación de la ciencia literaria», en: La historia de la literatura como provocación, Península, Barcelona, 2000, p. 189.

26 Ibid., p. 190. 
negativa que toma tanto de Popper como de Buck y que básicamente consiste en una frustración de la expectativa del intérprete. Pero lo más importante es que tal frustración no ejerce un efecto pedagógico por el mero hecho de que nos incita a reconsiderar el contexto de nuestra experiencia pasada de tal modo que los hechos nuevos se integran en la unidad rectificada a través de una fusión de horizontes. El resultado positivo de la experiencia negativa es una toma de conciencia de sí mismo, y aquello de lo que nos volvemos conscientes son las razones que hasta ese momento han conducido la experiencia y que no han sido, en tanto que motivos conductores, sometidas a cuestionamientos. De este modo, la experiencia negativa tiene, en primer lugar, el carácter autorreflexivo de una experiencia de sí misma que libera al sujeto para un modo de experiencia cualitativamente nuevo. Podemos agregar que desde la perspectiva de la hermenéutica crítica este proceso de autorreflexión y crítica se realiza desde el parámetro de los presupuestos pragmático-trascendentales del habla que ofician como horizonte emancipatorio. 27

Refiriendo todo esto a la literatura, puede decirse que el lector no tiene que tropezar con un nuevo obstáculo antes de poder acceder a una nueva experiencia de la realidad. La lectura puede liberarlo de los prejuicios y constricciones de su vida real, forzándolo a renovar su percepción de las cosas. La literatura anticipa posibilidades aún no realizadas y amplía los límites de comportamiento social, porque el lector se sumerge en situaciones infinitamente posibles que bien podría nunca encontrar en la vida real. De esta manera, se da la «frustración de la expectativa» a través de la ruptura del horizonte de expectativa de Jauss, sin necesidad de pasar por las situaciones leídas, lo que muy pocas veces sería posible, y así la literatura expande las posibilidades de aprendizaje social y manifiesta un considerable poder emancipatorio.

En tal sentido y en franca oposición al formalismo, dice Jauss que el poder creador de la literatura preorienta nuestra experiencia no solamente por el hecho de que sea un arte que rompe, por la novedad de sus formas, el automatismo de la percepción cotidiana. A diferencia de lo que el credo formalista sostiene, la forma nueva en arte no sólo es «percibida por contraste con un trasfondo de otras obras y por asociación con ellas», sino que también habilita a otra percepción de las cosas, prefigurando un contenido de experiencia que se expresa a través de la literatura, antes de acceder a la realidad de la vida. ${ }^{28}$

Esta tesis de Jauss en un mismo movimiento nos permite cerrar el desarrollo conceptual de la empatía en Aristóteles y la reflexión en Brecht, a la vez que cuestiona fuertemente la reducción de las narraciones con función social a las novelas realistas que presenta Nussbaum. De esta forma abre especialmente a una amplia

27 En este punto podemos ver una fuerte diferenciación con el concepto de fusión de horizontes de Gadamer, pero también un importante acercamiento al enfoque de la hermenéutica crítica para la que la interpretación cuenta con un criterio de validación que permite identificar una mejor interpretación a la que se llega vía autorreflexión trascendental. Cf. pp. 2 y 3 de este trabajo.

28 Cf. Jauss, op. cit., p. 191. 
variedad de narraciones la misma posibilidad de propiciar el proceso de extrañamiento-reconocimiento, como hemos visto en los pasajes citados de El país de las últimas cosas. La restricción de Nussbaum a la novela realista se basa en su concretitud, que a diferencia de otros géneros presenta formas de necesidad y deseo humanos encarnados en situaciones sociales específicas. Esto es reforzado por el interés de la novela en lo cotidiano, que se convierte en el objeto del interés y la compresión más profunda, lo que permite introducir al lector en lo que le es común y próximo pero que puede ser extraño y rechazado. ${ }^{29}$

Si bien estas razones son compartibles, sostendremos que esta particularidad no es exclusiva de la novela realista, sino que es algo accesible a todos los géneros, porque no sólo la generación de empatía entre el mundo del personaje y del lector no es parte de un género especial, sino que es algo inherente a toda la literatura. Para ello, además de lo ya expuesto de la posición de Jauss, apelaremos al concepto de mundo del texto introducido por Ricoeur y claramente sucedáneo del mundo de la vida de Husserl o del ser-en-el mundo de Heidegger.

La particularidad de la obra literaria reside en la modificación del carácter de la referencia -i.e. aquello a lo que la obra se refiere- puesto que, a diferencia de lo que ocurre con el discurso ordinario en el que siempre es posible apelar a la ostensión, en el texto literario, al ser una ficción, no hay situación común al escritor que lo permita, lo que habilita la posibilidad de que quede suprimida toda referencia a la realidad. De esta manera, la literatura asume como su función el atentar contra el mundo, contra su referencia.

La función de la mayor parte de nuestra literatura parece ser la de destruir el mundo. Esto vale para la literatura de ficción -cuento, novela breve, novela, teatro-, pero también para toda la literatura que se puede considerar poética, donde el lenguaje es glorificado por él mismo a expensas de la función referencial del discurso ordinario. ${ }^{30}$

Sin embargo, esto no impide que el discurso se conecte con la realidad, sólo que no a través de la referencia ya anulada por la ficción, sino a través de la introducción del mundo de la vida, que es todo aquello que la literatura no puede dejar de tener en común con el mundo real, porque es desde ese mundo real que la literatura se escribe. Es justamente esta originalidad en la forma de referir la que plantea el problema hermenéutico básico, ya que interpretar consistirá en la explicitación de este mundo de la vida accesible desde el texto, que Ricoeur denomina el mundo del texto.

Como ya mencionamos antes, esta explicitación del mundo a través de la actividad interpretativa siempre se realizará en términos de fusión de horizontes, por lo que siempre el intérprete proyectará su propio horizonte en la interpretación de la obra. Este horizonte, a su vez, requiere para acceder al mundo del texto que se cumpla la condición de la propia vulnerabilidad, ya que nadie que carezca de ella

${ }^{29}$ Cf. Nussbaum, op. cit., p. 35-36.

30 Ricoeur P., Del texto a la acción, FCE, México, 2000, p. 107. 
podrá generar las bases para el reconocimiento del otro a través de la empatía y la compasión.

De esta forma es como la literatura, por una característica propia y a través de todos sus géneros, ocupa un lugar de privilegio en los procesos posibilitantes del reconocimiento del otro, y en virtud de ello es una herramienta formidable para la educación ciudadana y un elemento dinamizador de toda discusión pública. Esa característica se extiende a todos sus géneros, propiciando tanto los relatos fantásticos como los realistas, momentos de apertura del mundo del texto que posibilitan que el procedimiento extrañamiento-reconocimiento se precipite en el lector. De tal forma la novela realista o fantástica, los relatos de ciencia ficción, la tragedia o la comedia se convierten en un aliado de primer orden en esta construcción de ciudadanía cosmopolita que hemos presentado como objetivo. 